\title{
The Effect of Trust Seals, Information Disclosure, and Gender on Customers' Trust and Willingness to Disclose Personal Information on Small B2C E-Commerce Website
}

\author{
Andree E. Widjaja ${ }^{1}$, Erik Paolo Capistrano ${ }^{2}$, Quang-An $\mathrm{Ha}^{3}$ \\ \{andree.widjaja@uph.edu' ${ }^{1}$, escapistrano@up.edu.ph ${ }^{2}$, anhq@ueh.edu.vn ${ }^{3}$ \} \\ Department of Information System, Universitas Pelita Harapan, 1100 M.H. Thamrin Boulevard, \\ Lippo Karawaci, Tangerang, Banten 15811 Indonesia $^{1}$, Department of Business of Administration, \\ University of the Philippines, UP Diliman, Quezon City 1101, Philippines ${ }^{2}$, School of International \\ Business and Marketing, University of Economics Ho Chi Minh City, 59C Nguyen Dinh Chieu, Phuong \\ 6, Quan 3, Thanh pho Ho Chi Minh, Vietnam ${ }^{3}$
}

\begin{abstract}
Drawing from cue utilization and signaling theory, this study aims to examine the effect of trust seals, information disclosure, gender, and its interactions on customers' trust and willingness to disclose personal information in the context of small B2C Ecommerce website. A full factorial $2 \mathrm{X} 2$ between-subject experimental design was conducted and there were 280 participants participated in this study. Our findings suggest that: 1). The presence of trust seals in the small B2C e-commerce website has a strong positive impact on trust and willingness to disclose. 2). The presence of trust seals is only useful when online retailer requesting a high degree of information disclosure. 3). Under conditions of a high degree of information disclosure, the effect of trust seals on willingness to disclose is more significant in male than in female. 4). There is a positive relationship between trust and willingness to disclose.
\end{abstract}

Keywords: Trust seals, information disclosure, gender, trust, willingness to disclose personal information.

\section{Introduction}

Over the past few years, the use of e-commerce has created an environment in which individual behaviors are altered. The current e-commerce technologies have aggravated the traditional perceptions of trust [1] as we know it since the customers' data collection and processing capacities have dramatically increased. These challenges are more prominent for small online retailers such as small medium enterprises (SMEs) wishing to go online and take their business to the Internet [2]. Moreover, it is shown that there is a growing trend that many SMEs have been shifting their traditional businesses into online, for instance by developing their own B2C e-commerce websites [3]. These small online retailers who have their own B2C e-commerce website may experience serious difficulties in gaining customers' trust as well as requesting customers' personal information. A common and widely known approach to cultivate trust is through the use of trust seals [4], [5], such as those provided by the more popular ones like TRUSTe and VeriSign. However, studies have consistently shown that there 
is still some confusion as to its impacts on transaction outcomes [6] and on behavioral issues such as information disclosure [4], [7], [8]. To date, there has been a plethora of prior studies examining the effect of web assurance seals on customers' related behaviors [9]-[12]. However, to the best of our knowledge, still little is known as to the effects of trust seals, information disclosure, gender, and its interactions on customers' trust and willingness to disclose personal information in the context of small B2C e-commerce website.

This study therefore tries to fill the research gap by answering the following research question "what are the effects of trust seals, information disclosure, and gender on customers' trust and willingness to disclose personal information in the context of small B2C e-commerce e-website". Thus, the main objective of this study is to empirically examine the effects of the three independent variables on the two dependent variables aforementioned. To better explain the link between independent variables and dependent variables, cue utilization theory and signaling theory are used. This study consequently contributes to the applicability of cue utilization and signaling theory in e-commerce context. Besides, this study also contributes to the extant e-commerce literature by providing some new insights with regard to the effect of trust seals, information disclosure, gender, and its interactions on customers' trust and willingness to disclose personal information in the context of small B2C e-commerce website. The findings of this study can shed light on the small online retailers (SMEs) who have just designed their B2C e-commerce website, and started their online businesses.

\section{Literature review}

\subsection{Theoretical foundation and research framework}

Cue utilization theory and signaling theory will be used as the theoretical foundation of this study. Cue utilization posits that an individual's process of evaluating a particular observation can be drawn from two sets of cues, intrinsic and extrinsic cues. But in the absence of intrinsic cues, extrinsic cues take over [13]. This situation can occur wherein customers have no prior experience (no intrinsic cues) dealing with a particular online retailer [4] such as small online retailers (SMEs). Therefore, when customers encounter a new online retailer, they are forced to draw from extrinsic cues (in this case the trust seals and information disclosure), and based on those cues they will make their evaluations [14]. Meanwhile, signaling theory posits that when in uncertain situations or there is information asymmetry, consumers attend to particular kinds of information cues that can help them to make a decision [15]. Meanwhile, signaling theory can explain how effective the infrastructure is in providing cues [2]. In the context of online environments, customer may draw upon the content and network information available in the website to make decisions [16]. Drawing from cue utilization and signaling theory, we propose our research framework as seen in Figure 1. There are five variables included in this framework, namely trust seals, information disclosure, gender, trust, and willingness to disclose personal information. 


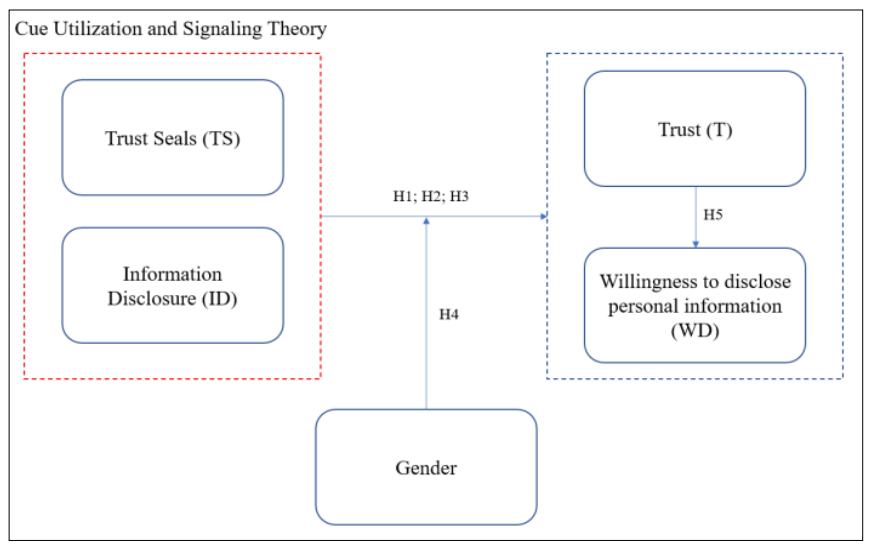

Fig. 1.Research framework.

\subsection{Trust and willingness to disclose personal information}

In any instance of online activity, trust will always be a central consideration. Trust is considered to be a very valuable business asset [17] especially in online environments where not all the parties involved necessarily know each other. For most cases, the burden of proving trustworthiness falls upon the retailer, especially if that retailer is a relatively new one, with no prior interactions with consumers to base trust on [6], [18], and hence, no reputation and feedback as of yet. Consumers prefer exchanges that are explicitly built on trust to encourage willingness to provide information [19], [20]. This further implies that if customers trust the company, they will provide complete and truthful personal information [21]. This is most especially true for new and small companies and products with little or no prior public exposure [4].

\subsection{Trust seals, information disclosure, and gender}

Seals of approval, or more commonly known as trust seals, are a common alternative to convey these signals and cues of a website's trustworthiness [5], [22] and reducing uncertainties [6], especially for small, lesser known online retailers that face harder and more difficult challenges to develop and cultivate trust [4]. Trust seals are predominantly provided by third party assessors, which add to the credibility of the online retailer since third parties are supposed to be independent and unbiased [17]. Some of the more notable third parties are TRUSTe and VeriSign [6]. Ideally, these trust seals provide opportunities for customers to assess these online retailers' trustworthiness [23], thereby increasing customers' trust [9], [11], [24] and willingness to disclose their personal information [8]. Along the lines of online personal information collection, another concern is related to the customer's perceptions on information sensitivity [25], which has been observed to also influence information disclosure behavior [7]. Companies have grown more intrusive and comprehensive about the quantity of personal information being collected and the practices to collect personal information [26], violating traditional boundaries of information privacy. In other words, the more information and the more sensitive this information is being asked for, the lesser the trust, and ultimately the lesser the willingness to provide personal information [27]. Furthermore, it was found that gender can predict information disclosure [28]. 


\subsection{Hypotheses development}

In this study, we propose nine hypotheses based on the theoretical foundations, the reviews of related literature, and some arguments that were made aforementioned. The following four hypotheses are related with the main (direct) effect of trust seals (TS) and information disclosure (ID) on customers' trust (T) and customers' willingness to disclose personal information (WD): Hla: The presence of TS will induce greater T; HIb: The presence of TS will induce greater WD; H2a: Higher ID request will induce lesser T; H2b: Higher ID request will induce lesser WD. Since ID was found to be influenced by T [27], we argue that TS might also interact together with ID. The following two hypotheses are related with the interaction effects of TS and ID on T and WD: H3a: There will be interaction effects between TS and ID on T; H3b:There will be interaction effects between TS and ID on WD. The effect of gender on ID was demonstrated by previous study [28]. It is also possible that gender will interact together with TS and ID influencing T and WD. Hence, the following two hypotheses are proposed: H4a: There will be interaction effects among TS, ID, and gender on T, such that gender will interact (moderate) with TS and ID influencing T; H4b: There will be interaction effects among TS, ID, and gender on WD, such that gender will interact (moderate) with TS and ID influencing WD. The final hypothesis is related with the relationship of T and WD: H5: $T$ is positively associated with WD.

\section{Methodology and data analysis}

\subsection{Research methods}

An online experiment was chosen as the research method in this study. We employed a full 2X2 factorial between-subject experimental design [29], in which two independent variables (trust seals and information disclosure) were manipulated into two treatments (high and low) There were four scenarios (A, B, C, and D) and each of the scenarios had its own specific manipulated treatments based on the two independent variables combinations. For instance, scenario A had high trust seals and high information disclosure, whereas scenario D had low trust seals and low information disclosure. These scenarios were represented by four distinct experimental websites simulating a small B2C e-commerce website which sold fictional innovative technology products to the customers. The included measurement items were mostly adapted from previous studies, measured by 7 point Likert scales $(1=$ strongly disagree to 7 = strongly agree), with some trivial modifications to fit this study's context [21][30]. There were 280 participants took part in our online experiment. The participants were undergraduate and graduate students, and they were recruited using the convenience sampling approach [31] in one of the well-known universities in southern Taiwan. After filling the consent form, the 280 participants were randomly and equally assigned into one of the four specific scenarios (websites), thus each scenario consisted of 70 participants. Each participant was then required to read the instructions and take careful attention to the user interface on the given website. A series of manipulation check procedures were performed to ensure the treatments' manipulations were effectively perceived by participants. After spending a few minutes viewing the website, they had to fill the survey (trust and willingness to disclose personal information measurement items) and finally they were thanked and dismissed. 


\subsection{Data analysis}

Based on the collected data (data source $=280$ participants), several data analysis procedures were performed using SPSS version 19 , namely descriptive statistics, confirmatory factor analysis (CFA), multivariate analysis of variance (MANOVA), and multiple regression analysis [32]. First, demographics information $(n=280)$ was analyzed, for instance, there were 137 males and 143 females. Second, the CFA was performed on the two dependent variables to confirm that all items were reliable and valid to be used for further data analysis. We followed CFA rule of thumb, such as factor loading $>0.6, \mathrm{KMO}>0.5$, commonality > 0.5 , Eigen-value $>1$, cumulative explained $>60 \%$, and Cronbach's Alpha $(\alpha)>0.7$ [32]. Our CFA results showed that all the requirements were met, thereby all items were considered reliable and valid. Third, MANOVA was performed to test hypothesis 1-4. All items in each dependent variable (T: T1-T5 and WD: WD1-WD5) were averaged accordingly and then used in MANOVA mean comparisons. The results showed some significant results. For trust variable, there was a significant difference between low TS and high TS $(3.697<4.517 ; \mathrm{F}=$ $34.540, \mathrm{p}<0.001)$, hence supporting hypothesis 1a. There were interaction effects between TS and ID ( $\mathrm{F}=22.790, \mathrm{p}<0.001)$, hence supporting hypothesis $3 \mathrm{a}$. Meanwhile, for WD, there was also a significant difference between low TS and high TS $(3.171<3.858 ; \mathrm{F}=15.350, \mathrm{p}<0.001)$, hence supporting hypothesis $1 \mathrm{~b}$. There were interaction effects between TS and ID ( $F=9.671$, $\mathrm{p}<0.001$ ), hence supporting hypothesis $3 \mathrm{~b}$. The other interaction effects among TS, ID, and Gender were also shown $(\mathrm{F}=5.524, \mathrm{p}<0.001)$, hence supporting hypothesis $4 \mathrm{~b}$. Based on MANOVA results, the unsupported hypotheses are hypothesis $2 a, 2 b$, and $4 a$. Finally, multiple regression analysis was performed to test hypothesis 5 . We followed the evaluation criteria as suggested by [32], such as $\mathrm{R}^{2}>0.1$, Durbin-Watson value should be between $1.5-2.5, \mathrm{t}>1.96$, and $\mathrm{F}>4$. The regression was performed by including control variables (gender, age, computer skills, and online shopping experience) and $\mathrm{T}$ variable. The regression model was performed twice, model 1 (only control variables) and model 2 (both control variables and $\mathrm{T}$ included). Based on model 2 results, it was shown that there was a very strong positive relationship between $\mathrm{T}$ and WD (Beta coefficient $=0.618, \mathrm{p}<0.001$, and adjusted $\mathrm{R}^{2}=0.427$ ), hence strongly supporting hypothesis 5 .

\section{Research results and discussions}

Based on the data analysis results, out of 9 hypotheses formulated in this study, there were six supported hypotheses (1a, 1b, 3a, 3b, 4b, and 5) and three unsupported hypotheses (2a, 2b, and $4 a)$. Hypothesis $1 \mathrm{a}$ and $1 \mathrm{~b}$ are supported, showing that the presence of TS do have a strong positive impact on both $\mathrm{T}$ and WD. Our results are consistent with some previous studies [4], [9], [24]. There are some evidences that $\mathrm{T}$ was served as one of the important predictors of customers' intention to buy [22], [33]. This means, the presence of TS in a small B2C ecommerce website, will greatly affect customers to have positive evaluations regarding the online retailer's website through $\mathrm{T}$ and $\mathrm{WD}$, which in turn might also contribute to their purchasing decisions. The purpose of this study is to empirically investigate the effect of TS, $\mathrm{ID}$, and gender on customers' $\mathrm{T}$ and $\mathrm{WD}$ within the context of small $\mathrm{B} 2 \mathrm{C}$ e-commerce website. We used cue utilization theory and signaling theory as the theoretical foundations for our research framework, in which it consists of five variables and nine hypotheses. To test our hypotheses, an online experiment with a full $2 \mathrm{X} 2$ factorial between-subject experimental 
design was conducted by involving 280 participants. Based on data analysis results, out of nine hypotheses, six hypotheses are supported, while three hypotheses are unsupported. This study has four major findings, they are: 1). The presence of TS in the small B2C e-commerce website has a strong positive impact on T and WD. 2). The presence of TS is only useful when online retailer requesting a high degree of ID (much personal information requested in the website). 3). Under conditions of a high degree of ID, the effect of TS on WD is more significant in male than in female. 4). There is a positive relationship between $\mathrm{T}$ and WD.

\section{References}

[1] G. R. Milne and S. Bahl, "Are there differences between consumers' and marketers' privacy expectations? A segment- and technology-level analysis," J. Public Policy Mark., vol. 29, no. 1, pp. 138-149, 2010, doi: 10.1509/jppm.29.1.138.

[2] S. Wang, S. E. Beatty, and W. Foxx, "Signaling the trustworthiness of small online retailers," J. Interact. Mark., vol. 18, no. 1, pp. 53-69, 2004, doi: 10.1002/dir.10071.

[3] Unido, "E-commerce development report of the small and medium sized enterprises of BRICS countries," 2018. [Online]. Available: https://www.unido.org/sites/default/files/files/2018-07/Ecommerce Development Report \%28SASS\%29_09072018.pdf.

[4] X. Hu, G. Wu, Y. Wu, and H. Zhang, "The effects of Web assurance seals on consumers' initial trust in an online vendor: A functional perspective," Decis. Support Syst., vol. 48, no. 2, pp. 407-418, 2010, doi: 10.1016/j.dss.2009.10.004.

[5] Z. Tang, Y. J. Hu, and M. D. Smith, "Gaining trust through online privacy protection: Selfregulation, mandatory standards, or Caveat Emptor," J. Manag. Inf. Syst., vol. 24, no. 4, pp. 153-173, 2008, doi: 10.2753/MIS0742-1222240406.

[6] K. Özpolat, G. G. Gao, W. Jank, and S. Viswanathan, "The value of third-party assurance seals in online retailing: An empirical investigation," Inf. Syst. Res., vol. 24, no. 4, pp. 1100-1111, 2013, doi: $10.1287 /$ isre.2013.0489.

[7] K.-L. Hui, H. H. Teo, and S.-Y. T. Lee, "The value of privacy assurance: An exploratory field experiment," MIS Q., vol. 31, no. 1, pp. 19-33, 2007, doi: 10.1177/0969733007082112.

[8] C. Mutimukwe, E. Kolkowska, and Å. Grönlund, "Information privacy in e-service: Effect of organizational privacy assurances on individual privacy concerns, perceptions, trust and selfdisclosure behavior," Gov. Inf. Q., vol. 37, no. 1, 2020, doi: 10.1016/j.giq.2019.101413.

[9] K. Rouibah, P. B. Lowry, and Y. Hwang, "The Effects of Perceived Enjoyment and Perceived Risks on Trust Formation and Intentions to Use Online Payment Systems: New Perspectives from an Arab Country," Electron. Commer. Res. Appl., vol. 19, pp. 33-43, 2016, doi: 10.2139/ssrn.2810637.

[10] M. Mousavizadeh, D. J. Kim, and R. Chen, "Effects of assurance mechanisms and consumer concerns on online purchase decisions: An empirical study," Decis. Support Syst., vol. 92, pp. 79-90, 2016, doi: 10.1016/j.dss.2016.09.011.

[11] Y. Wang and C. Herrando, "Does privacy assurance on social commerce sites matter to millennials?," Int. J. Inf. Manage., vol. 44, pp. 164-177, 2019, doi: 10.1016/j.ijinfomgt.2018.10.016.

[12] J. Lansing, N. Siegfried, A. Sunyaev, and A. Benlian, "Strategic signaling through cloud service certifications: Comparing the relative importance of certifications' assurances to companies and consumers," J. Strateg. Inf. Syst., vol. 28, no. 4, 2019, doi: 10.1016/j.jsis.2019.101579.

[13] D. F. Cox, "The Sorting Rule Model of the Consumer Product Evaluation Process," in Risk Taking and Information Handling in Consumer Behavior, Boston: Division of Research, Graduate School of Business Administration, Harvard University, 1967, pp. 317-369.

[14] K. B. Monroe and R. R. Akshay, "The Moderating Effect of Prior Knowledge on Cue Utilization in Product Evaluations," J. Consum. Res., vol. 15, no. 2, pp. 253-264, 1988.

[15] D. E. Kaun and A. M. Spence, Marketing Signaling: Informational Transfer in Hiring and Related Screening Processes., vol. 29, no. 1. Cambridge, MA: Harvard University Press, 1975. 
[16] A. Benlian and T. Hess, "The signaling role of IT features in influencing trust and participation in online communities," Int. J. Electron. Commer., vol. 15, no. 4, pp. 7-56, 2011, doi: 10.2753/JEC1086-4415150401.

[17] R. . Kramer, "Rethinking trust," Harv. Bus. Rev., vol. 87, no. 6, pp. 69-77, 2009, doi: 10.5840/bpej1997161/2/38.

[18] M. K. Chang, W. Cheung, and M. Tang, "Building trust online: Interactions among trust building mechanisms," Inf. Manag., vol. 50, no. 7, pp. 439-445, 2013, doi: 10.1016/j.im.2013.06.003.

[19] T. Dinev, P. Hart, and M. R. Mullen, "Internet privacy concerns and beliefs about government surveillance - An empirical investigation," J. Strateg. Inf. Syst., vol. 17, no. 3, pp. 214-233, 2008, doi: $10.1016 /$ j.jsis.2007.09.002.

[20] A. D. Smith, "Customer loyalty card programmes and its interaction with support technology in the retail industry," Int. J. Manag. Enterp. Dev., vol. 5, no. 2, pp. 157-195, 2008, doi: 10.1504/IJMED.2008.016971.

[21] J. C. Zimmer, R. E. Arsal, M. Al-Marzouq, and V. Grover, "Investigating online information disclosure: Effects of information relevance, trust and risk," Inf. Manag., vol. 47, no. 2, pp. 115-123, 2010, doi: 10.1016/j.im.2009.12.003.

[22] K. Özpolat and W. Jank, "Getting the most out of third party trust seals: An empirical analysis," Decis. Support Syst., vol. 73, pp. 47-56, 2015, doi: 10.1016/j.dss.2015.02.016.

[23] D. H. McKnight, V. Choudhury, and C. Kacmar, "Developing and validating trust measures for e-commerce: An integrative typology," Inf. Syst. Res., vol. 13, no. 3, pp. 334-359, 2002, doi: 10.1287/isre.13.3.334.81.

[24] H. Li, J. Jiang, and M. Wu, "The effects of trust assurances on consumers' initial online trust: A two-stage decision-making process perspective," Int. J. Inf. Manage., vol. 34, no. 3, pp. 395405, 2014, doi: 10.1016/j.ijinfomgt.2014.02.004.

[25] A. Balapour, H. R. Nikkhah, and R. Sabherwal, "Mobile application security: Role of perceived privacy as the predictor of security perceptions," Int. J. Inf. Manage., vol. 52, 2020, doi: 10.1016/j.ijinfomgt.2019.102063.

[26] K. S. Schwaig, A. H. Segars, V. Grover, and K. D. Fiedler, "A model of consumers' perceptions of the invasion of information privacy," Inf. Manag., vol. 50, no. 1, pp. 1-12, 2013, doi: 10.1016/j.im.2012.11.002.

[27] G. Bansal, F. M. Zahedi, and D. Gefen, "The impact of personal dispositions on information sensitivity, privacy concern and trust in disclosing health information online," Decis. Support Syst., vol. 49, no. 2, pp. 138-150, 2010, doi: 10.1016/j.dss.2010.01.010.

[28] K. F. Hew, "Students' and teachers' use of Facebook," Comput. Human Behav., vol. 27, no. 2, pp. 662-676, 2011, doi: 10.1016/j.chb.2010.11.020.

[29] F. N. Kerlinger and H. B. Lee, Foundations of behavioral research. Singapore: Thomson Learning, 2000.

[30] S. Bellman, E. J. Johnson, S. J. Kobrin, and G. L. Lohse, "International differences in information privacy concerns: A global survey of consumers," Inf. Soc., vol. 20, no. 5, pp. 313324, 2004, doi: 10.1080/01972240490507956.

[31] M. Saunders, P. Lewis, and A. Thornill, Research methods for business students. USA: Pearson, 2015.

[32] J. F. Hair, Wi. C. Black, B. J. Babin, and R. E. Anderson, Multivariate data analysis, 7th ed. Essex: Pearson, 2014.

[33] D. J. Kim, M. S. Yim, V. Sugumaran, and H. R. Rao, "Web assurance seal services, trust and consumers' concerns: An investigation of e-commerce transaction intentions across two nations," Eur. J. Inf. Syst., vol. 25, no. 3, pp. 252-273, 2016, doi: 10.1057/ejis.2015.16. 